\title{
Das Humboldt Forum und die Ethnologie
}

\section{Hélène Ivanoff}

\section{OpenEdition \\ Journals}

Édition électronique

URL : http://journals.openedition.org/ifha/10433

DOI : $10.4000 /$ ifha. 10433

ISSN : 2198-8943

Éditeur

IFRA - Institut franco-allemand (sciences historiques et sociales)

\section{Référence électronique}

Hélène Ivanoff, "Das Humboldt Forum und die Ethnologie », Revue de I'IFHA [En ligne], Date de recension, mis en ligne le 21 novembre 2019, consulté le 24 septembre 2020. URL : http://

journals.openedition.org/ifha/10433 ; DOI : https://doi.org/10.4000/ifha.10433

Ce document a été généré automatiquement le 24 septembre 2020.

(CIFHA 


\section{Das Humboldt Forum und die Ethnologie}

Hélène Ivanoff

\section{RÉFÉRENCE}

Das Humboldt Forum und die Ethnologie. Ein Gespräch zwischen Karl-Heinz Kohl, Fritz Kramer, Johann Michael Möller, Gereon Sievernich, Gisela Völger, Frankfurt-am-Main: Kula, 2019, 164 p., $17 €$ 
Au-delà des polémiques qui n'ont cessé d'accompagner la conception et la construction du Humboldt Forum de Berlin, ce livre donne matière à penser. Il accorde la parole à des spécialistes des collections extra-européennes, auxquelles ce musée sera dédié : des ethnologues et des directeurs de musées. Parmi eux KarlHeinz Kohl, professeur d'ethnologie à Mayence et à Francfort-sur-le-Main et ancien directeur de l'Institut Frobenius, Fritz Kramer qui a enseigné l'ethnologie à Berlin et la théorie de l'art à Hambourg, spécialiste de l'Asie du Sud-Est, Johann Michael Möller qui a étudié, entre autres l'ethnologie, journaliste et modérateur de ce dialogue, Gereon Sievernich, directeur du Martin-Gropius-Bau à Berlin jusqu'en 2018 , et Gisela Völger qui a dirigé pendant 20 ans le Rautenstrauch-Joest-Museum de Cologne.

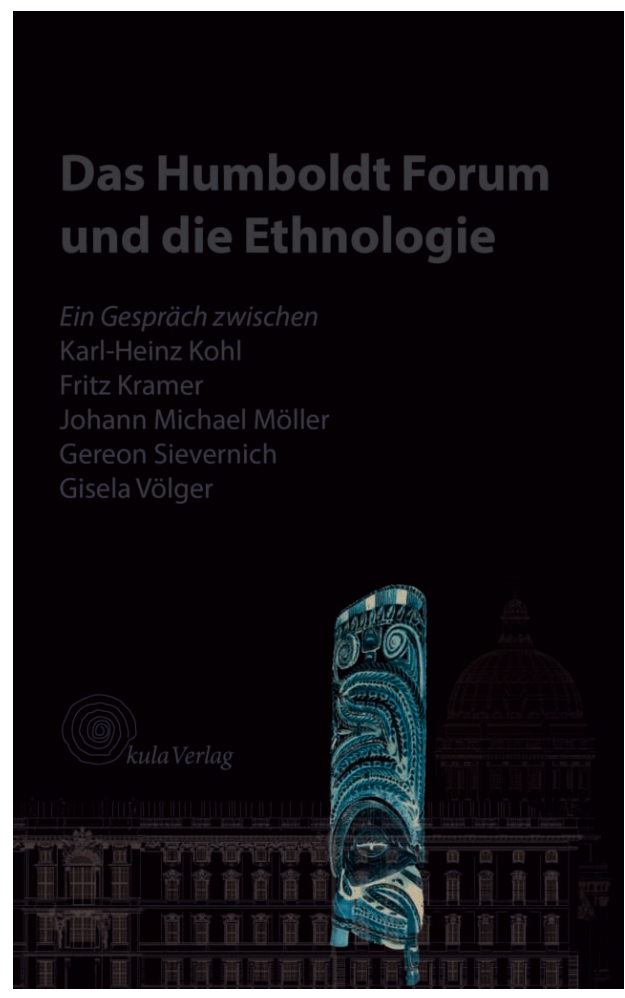

S'il s'adresse au grand public, l'ouvrage

comble un vide en faisant intervenir des spécialistes qui reviennent sciemment sur chacun des points litigieux du projet, notamment l'histoire d'une discipline l'ethnologie - que beaucoup aurait souhaité voir mieux représentée, tant au sein des débats publics qu'au cœur du projet. Sous la forme d'échanges constructifs, où les lignes de démarcations entre les interlocuteurs sont fluctuantes selon les sujets abordés, le livre revient sur les ambitions du projet et ses «malformations congénitales tragi-comiques » selon l'expression de F. Kramer. D'après lui, une erreur de conception s'est glissée dès le départ dans le projet qui cherche à évoquer la globalisation et le dialogue des cultures contemporaines en s'appuyant sur des collections ethnographiques extra-européennes qui relèvent majoritairement du passé.

Elles sont en effet le reflet de la culture de sociétés traditionnelles des temps coloniaux et à ce titre peuvent essentiellement incarner des représentations des cultures locales $\mathrm{du}$ monde. Encore faudrait-il préciser: telles qu'elles furent perçues par l'Europe dominatrice $\mathrm{du} \mathrm{XX}^{\mathrm{e}}$ siècle, car aucune collecte n'est objective et les collections extraeuropéennes nous en apprennent parfois plus sur les sociétés européennes qui les ont constituées que sur celles qui étaient sous leur emprise. Le risque est ainsi de transmettre une image quelque peu arriérée à la fois des sociétés extra-européennes et de la recherche ethnologique d'aujourd'hui. Pour le résumer avec les mots de F. Kramer: au Humboldt Forum, l'Australie sera représentée par le boomerang et l'Amérique par des couronnes de plumes.

Le choix, jugé malheureux, de reconstruire l'ancien château des Hohenzollern inscrit, en particulier, le Humboldt Forum dans la lignée du projet impérialiste allemand, voire prussien, au lieu de le tourner vers l'avenir. Il devient dès lors difficile d'en faire le symbole du développement de nouvelles relations Nord-Sud ou l'emblème d'une métropole ouverte sur le monde avec une forte population immigrée. La faible place 
accordée à la consultation des ethnologues, pourtant experts de ces collections, suscite naturellement l'interrogation. Seules les équipes du Musée d'ethnologie et du Musée des arts asiatiques de Dahlem furent effectivement brièvement consultées, jusqu'à la nomination en 2015 au comité de direction du Humboldt Forum de Robert Neil MacGregor, ancien directeur du British Museum, de l'archéologue Hermann Parzinger et de l'historien d'art Horst Bredekamp.

Dans le débat concernant les spoliations et les restitutions, il aurait été pourtant judicieux de mettre en avant les ethnologues. Comme en atteste le livre, leur connaissance de l'histoire des collections est indéniable, même si la provenance d'une partie d'entre elles reste incertaine et mérite encore des recherches approfondies. Plus que d'autres, ils apparaissent conscients des problèmes que soulève le retour des objets spoliés dans leur territoire d'origine. L'arrivée de R. N. MacGregor a probablement cristallisé les tensions sur ce point, puisque ses positions étaient connues en la matière, l'ancien directeur du British Museum opposant aux thèses post-colonialistes le principe d'un héritage partagé ou « shared heritage ».

Sans contester la légitimité d'une partie des demandes de restitution, les interlocuteurs rappellent dans ce livre ce qui peut paraître des évidences, mais qui est bien souvent étouffé par la ferveur postcoloniale, nationaliste ou communautaire, qui accompagnent parfois les réclamations. Les ethnologues ne furent pas tous partisans du colonialisme bien au contraire, même, dans le cas allemand. Les collections ethnographiques ne sont pas toutes tâchées de sang - à l'opposé, certaines ont été au cœur des échanges entre scientifiques et populations locales. Un pays européen ne peut se limiter à exposer des collections européennes - ne serait-ce que pour témoigner de l'histoire coloniale et, bien sûr, présenter les cultures du monde.

Cette réhabilitation de l'ethnologie allemande, mise à mal dans les débats publics en raison de sa compromission supposée avec le colonialisme, était nécessaire. À l'encontre des propos trop radicaux assimilant l'ensemble des collections à des pillages ou à des spoliations de la période coloniale, K.-H. Kohl souligne les représentations intellectuelles éclairées du XIXe siècle à la source de la constitution des collections ethnographiques extra-européennes et du savoir anthropologique. G. Sievernich et G. Völger dressent ensuite un tableau de la situation internationale des musées d'ethnologie ou des cultures du monde, en montrant notamment les relations établies par les musées avec les communautés d'origine et les minorités nationales, ainsi que leur attachement à la présentation de leur patrimoine dans les musées.

Dans le même temps, la conversation engagée laisse place aux opportunités qu'offrira ce nouveau musée pour l'ethnologie et sa visibilité dans l'opinion publique. En dépit d'un mauvais départ, les intervenants concluent donc sur une note positive, presque naïve et surprenante, au regard des désillusions apportées par la phase de conception du projet décrite préalablement. Certains osent rêver d'une harmonieuse coopération entre le dépôt demeurant à Dahlem, qui pourrait être entièrement dédié à la recherche - recherche ethnologique, certes, mais aussi de provenance où le passé des collections devrait être retracé avec précision - et le Humboldt Forum qui, idéalement, pourrait en diffuser les résultats.

Cette vision apparaît quelque peu utopiste compte-tenu des défiances existant parfois entre les universités et les musées. Pourtant associés pour le développement de la discipline jusque dans les années 1960, ils forment désormais deux mondes séparés, où il est devenu difficile de faire carrière conjointement. Le peu d'intérêt que suscite 
également l'histoire de la discipline auprès des ethnologues contemporains qui privilégient leur terrain, plus que des recherches sur les collections accumulées par leurs prédécesseurs, représente vraisemblablement aussi un frein à de futures coopérations, qui devra être levé.

Bien que le livre dresse un bilan pertinent et prometteur sur les relations entre le Humboldt Forum et l'ethnologie, on peut regretter que le propos ait été néanmoins limité à cette discipline et à l'intervention d'interlocuteurs allemands. À défaut et en l'absence de leaders représentatifs interviewés, les positions des communautés d'origine et des États postcoloniaux ne sont ainsi connues que par l'intermédiaire des ethnologues qui s'en font l'écho. Cette prise de parole tardive manifeste en outre les espoirs et les inquiétudes d'une seule discipline face à ce nouveau musée, loin de l'ambition de faire du Humboldt Forum un lieu de diffusion d'un savoir pluri- et transdisciplinaire, recourant aux compétences des ethnologues, mais aussi des historiens et des sociologues, pour inviter à un réel dialogue avec des partenaires étrangers ou avec la population immigrée de Berlin.

Le musée rencontrera certainement le succès du public au cœur de la capitale touristique et cosmopolite qu'est Berlin, mais un grand nombre de défis reste encore à relever pour répondre aux attentes politiques et scientifiques du projet. Ce livre prouve, une nouvelle fois, que la richesse et la finesse du discours ethnologique et sa compréhension des autres cultures peuvent incontestablement y contribuer.

\section{INDEX}

Thèmes : Histoire de l'art, Histoire de la culture, Histoire des mentalités

Index chronologique : Époque contemporaine 